\section{GOLDBERG-MAXWELL SYNDROME} REPORT OF THE ANOMALY IN THREE SISTERS

\author{
BY
}

RAMA VAISH, M.B., M.S., M.R.C.O.G. Lecturer in Obstetrics and Gynaecology, G.S.V.M. Medical College, Kanpur; Obstetric Surgeon, A.H.M. and Dufferin Hospital, Kanpur, Uttar Pradesh, India

In 1948 Goldberg and Maxwell described a case of feminine type of male pseudohermaphroditism and collected seven other cases from the literature which they believed belonged to the same group. Up till 1954, altogether 22 examples of Goldberg-Maxwell syndrome have been reported in the literature. Below is the report of this condition occurring in three sisters.

\section{Case Report}

A female Hindu, 21 years of age, married, was admitted at the A.H.M. and Dufferin Hospital, Kanpur, for the investigation and treatment of primary amenorrhoea. She looked perfectly feminine. Her height was $5 \mathrm{ft}$. Sin. $(1.65 \mathrm{~m}$.), chest 35 in. $(0.89 \mathrm{~m}$.$) , and waist 28$ in. $(0.71 \mathrm{~m})$. Her breasts were well developed and the areolae and nipples normal. Axillary and pubic hair were absent. On vaginal examination the external genitalia were found to be normal. The labia were shaped normally, the urethra was situated correctly, and the clitoris was of usual size. The vagina was of ordinary dimensions, being $3 \frac{1}{2}$ in. $(8.9 \mathrm{~cm}$.) in length and quite capacious. The vagina ended in a blind pouch and no cervix was felt or seen, the vaginal vault being a smooth dome with no elevation or depression. Nothing could be felt at the site of the uterus.

The patient had been married two years and was perfectly happy as the female partner. Her sexual inclinations were female and her libido was normal. Her family history was most interesting, as two of her sisters also showed the same abnormality. Her eldest sister, 25 years old, had been married for seven years, but had no children and had never menstruated. Unfortunately a physical examination could not be carried out on her as she was in Calcutta ; but from the description given by her sister it was quite obvious that she also suffered from the same anomaly. The second sister was 23 years old, and had been a widow for five years. She had never menstruated and had no issue. Her appearance was feminine and she had well-developed breasts, but axillary and pubic hair was absent. The external genitalia and vagina were normal; the latter ended in a cul-de-sac and the uterus and cervix were absent. The third, and youngest, sister was 12 years old, unmarried, and had small, adolescent breasts. The axillary and pubic hair had just started to appear and she had menstruated twice. External genitalia were normal. Rectal and vaginal examination could not be done. Skin specimens were taken for biopsy from the second and third sisters, but report on the nuclear sex could not be given as the preservation of tissue was not satisfactory.

Tests for the estimation of hormone levels in blood and urine could not be carried out owing to lack of facilities for hormone assay. Laparotomy was performed on July 25 , 1957. The findings were as follows. The uterus was absent, and in its place there was a tiny nodule of fibrofatty tisue. The tube, gonad, broad ligament, and round ligament were absent on the right side. On the left side the tube was absent; the broad ligament was very rudimentary, ending outwards in a thin crescentic fold. The left gonad was situated in the region of the left iliac fossa, attached by a fold of peritoneum to the posterior abdominal wall. It was about 3 in. $\left(7.6 \mathrm{~cm}\right.$.) long and $1 \frac{1}{2}$ in. $(3.8 \mathrm{~cm}$.) wide, and consisted of cysts $2 \mathrm{~mm}$. to $1 \mathrm{~cm}$. in diameter. A large piece was taken from the left gonad as a biopsy specimen, and the abdomen was closed.
The histological report on the specimen was: "Section shows number of tubular structures separated by a variable amount of fibro-collagenous stroma. These tubules are lined by one or two layers of rounded cubical cells. The cytoplasm of some of these cells is vacuolated or clear in appearance. The stroma in between these tubules contains small islands of Leydig cells. The latter are rounded or ovoid in shape, having intensely eosinophilic cytoplasm."

\section{Discussion}

Although only 22 cases of Goldberg-Maxwell syndrome have been described in the literature from 1948 to 1954 , the condition is not so uncommon. In the last 10 months, while working in this hospital, besides the above-mentioned cases of three sisters, I have found this condition also in another patient, who complained of primary amenorrhoea and sterility. A skin biopsy specimen was taken for nuclear sexing, but she did not report back. I think many of these cases are sent away by general practitioners as hopeless cases for treatment from the point of view of producing menstruation or pregnancy owing to the absence of the uterus.

The Goldberg-Maxwell syndrome comprises a very distinctive group of patients in whom the bodily habitus and sexual behaviour are essentially feminine. They are brought up as females, marry, and live as female partners. They consult the gynaecologist for primary amenorrhoea and sterility. The breasts are normal in size, but pubic and axillary hair is absent. The external genitalia-that is, the labia, urethra, clitoris, and vestibule-are normal in shape and situation. The vagina is of normal length and capacity; therefore there is no difficulty in coitus, and many of these patients are able to have orgasm. The vagina ends as a blind pouch, there being no cervix and uterus; although in some cases a fibro-fatty nodule or a vestigial uterus may be present.

The gonads are found in the abdomen, usually in the position of the ovaries, but may be situated elsewhere in the abdomen and attached to the posterior abdominal wall by a small mesentery. The broad and ovarian ligaments are absent or rudimentary. These gonads resemble an infantile type of ovary in appearance, being long. bulky, and lobulated. Cysts are sometimes present in their substance. On histological examination the gonads are found to be devoid of ovarian elements, but present the structure of immature, sterile; cryptorchid testes as typically found in the case reported in this article.

According to Goldberg and Maxwell, the urinary F.S.H. output is high (at least 96 M.U. in 24 hours), indicating primary gonadal deficiency; and 17-ketosteroid output is within normal range. Vaginal smears indicate a fair degree of oestrogenic stimulation of vaginal mucosa.

It has been said that the absence of pubic and axillary hair is a genetic abnormality comparable to the various congenital abnormalities found in ovarian agenesis or Turner's syndrome. Another feature of the GoldbergMaxwell syndrome is the very strong family incidence, as will be obvious from the above case report of three sisters and from Schneider's cases, six of which occurred in one family and were spread over three generations.

Although some authors advocate the removal of gonads for fear of occurrence of neoplasm in cryptorchid testes, this point is highly debatable. Removal of these gonads may lead to unpleasant climacteric disturbances, as the gonads are responsible for the production of oestrogens, and not the adrenal cortex as thought by some. For this reason the syndrome has also been described under the heading of "oestrogen-producing testes." Adrenocortical function has been tested in various ways in these cases, but impairment of function of adrenal glands has not been found.

The nuclear sex of these vases is male. Jost and other workers have carricd out certain experiments on animals by which they explain the occurrence of male nuclear patterns in these anatomically female cases. They postulate the 
female form to be the basic or neuter, and the male differentiation to occur only in the presence of functioning testes during development of the embryo. Graham, in his experimental study in cats, has pointed out that sex chromatin can be recognized in the early embryo before the gonads have appeared, and therefore the sex is genetically determined and does not depend upon the hormonal status of the individual. Hoffenberg and Jackson have explained the varieties of gonadal dysgenesis and the various forms of human intersex by postulating three closely connected genes situated on the same chromosome. These authors have postulated one gene for infantilism or intrauterine hypogonadism-called "I"; one gene for shortness of stature, "S"; and one gene-complex for various anomalies of vegetative system called "A." According to them, the infantilism in gonadal dysgenesis results from very early failure of the developing gonad (their factor I), with consequent feminization of genital tract and body form. If gonadal dysgenesis occurs at a later stage of the male embryonic development, partial development along masculine lines will already have taken place. Further development of the genital tract will be of the female type, and thus "male pseudohermaphroditism "will result. This is equivalent to their "I" factor coming into operation at a slightly later stage. They conclude thus: "I" alone (slightly later in genetic male)-male pseudohermaphroditism; "I" (slightly later in genetic male) $+\mathrm{S}+\mathrm{A}$-male pseudohermaphroditism with short stature and anomalies.

The observations of Jost and Graham have led to the adoption of the term "gonadal dysgenesis" in preference to "ovarian agenesis." It also suggests that the GoldbergMaxwell syndrome is, in fact, a variety of gonadal dysgenesis, where genetic development has failed in its attempt to produce a normally functioning testis and therefore the basic female pattern has continued. In this syndrome the failure to develop has probably occurred at a very early stage of development of the embryo, with the emergence of a complete feminine form and none of the male features. We can therefore say that the GoldbergMaxwell syndrome is the earliest form of male pseudohermaphroditism.

\section{Summary}

The syndrome of Goldberg and Maxwell occurring in three sisters has been described.

The various features of the syndrome have been surveyed in detail.

The genetic aspects of the syndrome have been discussed in the light of modern work, and a hypothesis is produced to account for the syndrome.

\section{BIBLIOGRAPHY}

Armstrong, C. N. (1955). Brit. med. J., 1, 1173.

Barr, M. L. (1954). Surg. Gynec. Obstet., 99, 184.

Beatty, D. C., Champ, C. J., and Swyer, G. I. M. (1953). Brtt. med J., 1, 1369.

Bishop. P. M. F. (1945) Guy's Hosp. Rep., 94, 12.

- (1954). Recent Advances in Endocrinology, 7th ed. Churchill, London. Cawadias, A. P. (1946). Hermaphroditos, The Human Intersex, 2nd ed. Heinemann, London.

Davidson, W. M., and Smith, D. R. (1954). Brit. med. J., 1, 1379.

Goldberg, M.B., and Maxwell, A. F. (1948). J. clin. Endocr., 8, 367.

Graham, M. A. (1954). Nature (Lond.), 173, 310.

Hoffenberg, R., and Jackson, W. P. U. (1957a). Brit. med. J., 1, 1281.

-1 (1957b). Ibid., 2, 1457.

Jost. A. (1953). Recent Progr. Hormone Res., 8, 379.

Moore, K. L., and Bart, M. L. (1955). Lancet, 2, 57.

Schneider. R. W.. Van Ommen, R. A., and Hoerr, S. O. (1952). J. clin. Endocr., 12. 423.

Selye, H. (195:)). Textbook of Endocrinology. Acta Endocrinologica, Montreal.

Soffer, L. J. (1956). Diseases of the Endocrine Glands, 2nd ed. Lea and Febiger, Philadelphia.

Swyer, G. I. M. (1955). Brit. med. J., 2, 709.

Williams, D. I. (1952). Itid., 1, 1264.

Wilkins, L. (1950). The Diagnosis and Treatment of Endocrine Disorders in Childhood and Adolescence. Thomas. Springfield.

Year Bnok of Endocrinology. 1955-1956 (1956). Year Book Publishers. Chicago.

\section{AN ERYTHROPOIETIC FACTOR PRODUCED IN THE KIDNEY PRELIMINARY REPORT}

\author{
BY
}

SVERRE OSNES, M.D.

From the Institute of General and Experimental Pathology, University of Oslo (Director: Professor L. Kreyberg, M.D.)

A systematic study has been made of the response in mice to $x$-irradiation of the kidneys. The exteriorized kidneys were exposed to a single $x$-ray irradiation. The doses ranged between 100 and $18,000 \mathrm{r}$. By irradiation of the kidneys in mice a condition was produced resembling the essential features of glomerulonephritis in man with increasing nitrogen accumulation in the blood, anaemia, acidosis, oedema, hypertonia with hypertrophy of the heart, atrophy and granulation of the kidneys, albuminuria, haematuria, cast formation, decreased concentration of the urine to isosthenuria, and final collapse in a uraemic condition.

\section{Experimental Findings}

After 8,000 to $12,000 \mathrm{r}$ increased blood pressure was cbserved in 10 days, whereas after $1,000 \mathrm{r}$ about 8-12 months was necessary for this development. After unilateral nephrectomy and irradiation of the remaining kidney with $500 \mathrm{r}$ the blood urea level increased in the course of five months. With the same procedure, and using $8,000 \mathrm{r}$, a rise in blood urea was observed after five days.

The anaemia caused by $x$-ray irradiation of the kidneys in mice was hypochromic to normochromic. The bone marrow showed a hypoplastic erythropoiesis.

In experiments with irradiation of the total amount of kidney tissue, the first changes observed were an increase of the blood urea level and a decrease in the haemoglobin values. Even at a time when the rise in blood urea was only from 20 to $23-24 \mathrm{mg}$. per $100 \mathrm{ml}$., a decrease in the haemoglobin value could be traced. It is therefore unlikely that the former caused the latter.

Through variation of the experimental procedure it has been possible to demonstrate the following.

1. In mice having a very small amount of kidney tissue shielded during the irradiation, the haemoglobin is maintained at a higher level than that usually found in connexion with the increased blood urea figures observed in these animals, and higher than in the animals with all the kidney tissue irradiated.

2. If one-quarter to one-third of one kidney is shielded during the irradiation the haemoglobin values may be maintained at the normal level, in spite of the development of

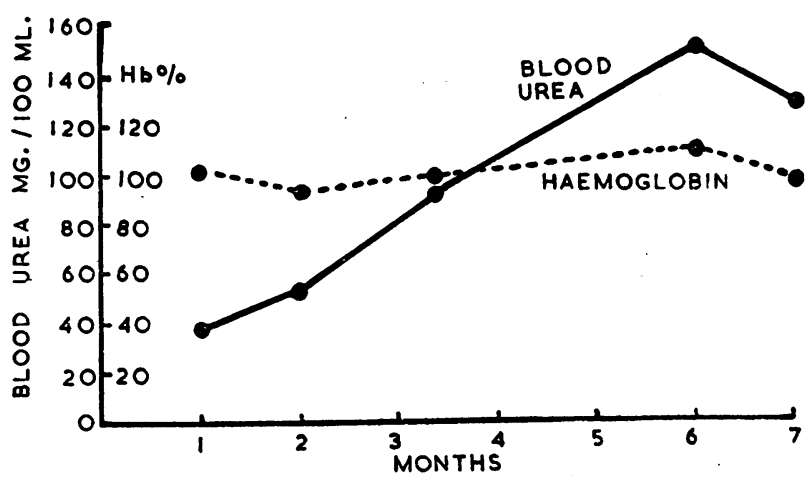

Blood urea and haemoglobin values in a mouse after unilateral nephrectomy and irradiation of approximately three-quarters of the remaining kidney with $8,000 \mathrm{r}$. 